\title{
Research on Application of Real Estate Marketing based on We-Media of WeChat Media
}

\author{
Hongyan Xin ${ }^{1, a}$, Chunming $A n^{1}$ \\ ${ }^{1}$ School of Economic Management, Beihua University, 132013, Jilin City, China. \\ aHongyan-xin@126.com
}

Keywords: Real estate marketing, We-Media, network

\begin{abstract}
In recent years, the domestic real estate industry development rapidly tends to be stable, but marketing means also is undergoing tremendous change, dropping from traditional advertising to the current network marketing in the marketing means with the real economic downturn. The real estate dealers is how to grasp the trend of the times, actively and effectively seize the opportunity, and strive to network technology in the media marketing rapid development time, through apply the WeChat ways, and pay attention to focus on the development of creative thinking in strategy, ideas and methods by powerful marketing means, give full play to promote the marketing effect, to their own advantages.
\end{abstract}

\section{Introduction}

Since the reform and opening up, the real estate industry after years of development, has been from scratch, from birth to the rise to prosperity and further development to today's increasingly stable, the real estate industry to the national economy, people's lives have caused a huge impact. From 1980 started the commercialization of housing in the national implementation of the policy, in 2003 the State Council Decree No. 18 will determine the real estate industry as a pillar industry of China's economy, then two sessions in 2015, Prime Minister Li Keqiang "Support from residents living in the government work report and improve housing demand and promote stable and healthy development of the real estate market, "the CPC Central Committee, State Council of real estate control policies continue to adjust according to the current situation. Currently, the central guidance, the real estate industry credit policy continued to relax its restriction policies forward step by step adjustment, property tax is gradually legalized and local governments have introduced deregulation policies, increased demand by the household registration deregulation, improve new urbanization level stock market and other digestive macroeconomic policy for the development of the real estate industry to provide healthy, beneficial platform. The real estate industry experienced a "golden decade" of development after gradually stabilized, not only greatly to the development of national economy has made a great contribution, greatly enhance and improve the people's livelihood, but also driven by a number of supporting industries and the development of downstream services, to promote the competitiveness of the regional economy provides a strong support.

In the real estate industry sustained and stable development of the background, along with economic development, extensive application of the Internet industry, real estate industry marketing has gradually undergone many changes. Mainly in two aspects compared to traditional push marketing approach, current news people to accept the way a lot of changes, more and more users prefer to read through the news media in the network, the use of micro Bo, micro letters and other interactive media, and traditional forms of advertising attention decreased; Second, after a series of national real estate regulation, the real estate industry, more and more regular, channels, and more transparent information, the traditional marketing means face enormous competitive new media, and even in the real estate marketing, various marketing tools are changing, have a huge impact for the real estate marketing.

In this case, since the micro-channel media marketing as a new marketing tool, gradually showing a huge advantage, mainly in three aspects: 
First class instant messaging has become an important field of giant competition. After the micro-channel was a huge amount of users and the platform started, major Internet companies have noticed that mobile instant messaging application as a huge potential for platform-level products, put efforts in this area. Although many products are mainly major Internet companies or carriers for micro-channel defensive measures, but if you get the same depth there will be further development initiatives. It can be seen mobile instant messaging type applications has become a hot field, and its development potential recognized in the industry.

Second, the application of light to become the future may form a mobile Internet. Micro-channel public platform gradually open interfaces, application developers can use these interfaces to launch their own applications on the public platform, can be called "light applications." After Baidu introduced the concept of "light application" in the Baidu World Congress. Baidu occupies an important entry of the mobile terminal, namely mobile search. Users can directly through the search page Subscribe to the "application of light", without the need to download the same as Native App. Short term, the mobile Internet is still the core of Native App, but Tencent and Baidu's product strategy, the light and the possibility of HTML5 application development on the Web App is also recognized.

Third, micro-channel to the traditional industry to embrace the mobile Internet provides an opportunity. Low threshold micro-channel public platform for traditional industries to embrace the mobile Internet provides more opportunities. Users public platform include not only some of the large-scale enterprises, including small businesses, or some of the original authors, stars. First, micro-channel to provide a simple, low cost and highly customizable platform, while users on this platform have sufficient scale, this is both an important platform for traditional industries of business entity for marketing opportunities and customer service platform, but it is also possible to achieve a direct channel profitability. In this case, since the micro-channel media in Real Estate Marketing research, not only to guide the development of the real estate industry, and theoretical study of network marketing also has some value.

\section{The Similarities and Differences of Media Marketing and Traditional Marketing}

Through the above-mentioned self-media, especially micro-channel self-analysis of comparative media marketing, from the same point media marketing and traditional marketing mainly reflected in three aspects, one subject of marketing and object are the same, are the distributors (main body) through specific media to potential users (object) brand, product, service output value content, explore user; the second is the same for marketing purposes, it is to enhance the brand value, promote sales; third form of marketing is the same, through the brand, products and services in the advantages of a comprehensive display.

In the "self-media real estate marketing slogan of change" is mentioned, from the media real estate marketing compared to traditional marketing, there are three characteristics are having a lot of Communication, information can quickly update information disseminator and recipient identity information in one. Through research, it can be distinguished from traditional media marketing characteristics summarized. (In conjunction with the line Online To Offline, online, it is the Internet as a platform to promote the Internet as a front office trading, the development of the line of business) in $\mathrm{O} 2 \mathrm{O}$ mode, micro-channel that has a strong geographical pattern (location-based information services), social applications, through the surrounding information services, in particular to promote the real estate industry service information line to grasp the entities in the same line at the combine to ensure that the medium (micro-channel circle of friends, the micro-channel public number) of active and stability, facilitate transactions offline. In Zhejiang beam Riverside Guri, Yi German mansion, Wanda International Resort Xishuangbanna and other case studies, good use of comprehensive micro Loushu marketing to promote the combination of online and offline.

Ensure developers during the process of micro-channel marketing in a timely, comprehensive, in-depth grasp of market dynamics, grasp the practical needs of the potential customer base, can be 
made from micro-channel media marketing can be targeted, and effective. Especially in Guangzhou Vanke cloud customer service mobile interactive platform, Guangzhou Vanke will use the number of people, covering a wide customer base growing micro letter from the media as the main service platform to create "data analysis + Operations Management" service platform, very good ensure the full range of information on the customer master.

In a timely manner through various means to push the user a variety of meaningful and valuable, users concerned about the high, high time-sensitive information, this can effectively ensure that users of micro-channel marketing services platform for recognition. In Zhejiang beam Riverside Guri estate micro-channel marketing cases through timely news push, especially the model of the watch, screaming send mobile phone, visit send movie tickets and other activities, through content push to publish, in a push content for an effective quality assurance, it is possible to achieve the desired results.

Expand multi-channel marketing path, combined with young, highly educated, active and use micro-channel groups, receptive to new things ability and other characteristics, we have introduced innovative services and activity patterns, raise awareness, open up marketing channels. R \& F Yeston building giant two-dimensional code display, two-dimensional code subway security show activities, all with eye-catching manner quickly won the people's attention, and sea salt on Everglade City • spring and secondary marketing WeChat Golden Lake center of the earth praise send gifts, we have been very good secondary promotion.

\section{Micro-channel Media Applications in the Real Estate Marketing}

4P marketing model (The Marketing g Theory of 4Ps), is a classic marketing model, founded in the 1960s, and there are Philip Kotler • in the "Marketing Management: Analysis, Planning and Control" to further clarify, also It is the product (product), price (price), channel (Place), publicity (Promotion) a combination of four basic strategies. Through traditional marketing and comparative media marketing from combining self-media marketing user-centered, fragmented, real-time, as well as two-way communication, this paper proposes 4PM model, respectively, from the product (Product), price (Price), channel (Place), case publicity (Promotion) and the media (media) of five specific analysis. Since media marketing, pay attention to the media through interactive features from the user to explore, therefore, on the basis of product, price, place and promotion, through the media since the Great For the amount of potential users, it has become a key marketing work. Brochure conducted using micro-channel real estate promotion process, the real estate positioning and indirectly to the client display. In particular, to seize the real estate sales in the "home" concept, the concept of fuss. WeChat Loushu core module also highlighted to build a "family" through the "house." Issued "in the yard of the family," micro-film, the family lives by memories of season's style talk, to create a harmonious family atmosphere, but also real estate positioning and good publicity. The use of "micro-movie" The brisk advertising model, in line with the user's actual micro-channel, user-friendly operation, to promote real estate can be a good publicity, but also to a large extent reduce customer forcibly push advertising messages rejection sense.

In real estate marketing, in order to achieve the effect of smoke powder, taken the advertising networks to promote the traditional manner. Traditional advertising methods, mainly through television, newspapers and other a lot of publicity on the "beams Riverside nine years," a lot of momentum, so that real estate have a certain influence, and local television, newspaper ads, launched "I sweep the two-dimensional code micro-channel public concern number" of the project; and network to promote, through Hang room online, SouFun, Tencent real estate network platform for publicity, by the same keyword search, sweep the two-dimensional code Following beam Riverside Guri micro signal. Through targeted screening and promotion, so that the micro-channel public number of users has reached a certain size, but also provides a good understanding of the real estate dynamic platform for potential users. 
In the early days a lot of momentum on the basis of a better description of the product, and to achieve the effect of "raising powder", in addition to publicity through newspapers, websites, the group also released a number of micro-channel public advertisement information, the activities time and place were pushed. In real estate marketing for accurate price positioning, and target prices with user features contact and accurately collect interaction data user characteristic data and the full life cycle of social-oriented customer relationship management has become the real estate industry information management concerned about the hot, many real estate companies have shortened the distance between businesses and users through the micro-channel, APP and other social applications to enhance communication and interaction. With the large number of users to generate interactive process characteristic information, mutual information, real estate companies want to maximize data collection, analysis of user traffic changes, user characteristics and behavior, predict user traffic trends and concerns to guide operational decisions. But based on the social model of the real estate industry has not yet become operational systems currently on the market all kinds of social software cannot operate the information collection, and traffic trend information collected after the user behavior analysis and forecast even more user attention and so cannot be realized. The fundamental reason is that the real estate industry on the user characteristic information, behavioral information collection broader.

\section{Real Estate Media Marketing Management Recommendations}

Micro letter this new media marketing, we first need to do on innovative strategies. Dominant strategy in order to ensure on advanced marketing tools. Since the media on real estate through micro-channel marketing, has been a gradual transition from testing the waters to the current stage in full swing, more and more companies began to try to use the micro-channel marketing. But not all companies use the same marketing methods can achieve good results, need to segment the sales market, a clear market positioning and customer type.

For real estate dealer, in order to make micro-channel marketing to achieve the desired effect, two aspects need to be clearly established in the market division and objectives: First, a clear use of micro-channel marketing tools to select from media marketing are using, marketing tools, need to combine with real estate marketing, feasibility and need to have to have a real estate marketing promotion, such as case studies show set up in the subway, if you simply show, the real estate marketing is not much sense but by displaying two-dimensional code on your tablet, it attracted the attention of both, it is possible to promote micro-channel public number, so that the passengers concerned to real estate, is valuable; the second is the type of customer targeted marketing clearly different Property, shops correspond to different types of customers, although during the micro-channel marketing, customer groups overall bias young, receptive to new things, but the economic strength of housing demand is also very different, so whether it is promoted in the micro-channel public number, content when push the line still active in the organization, we need to carefully grasp the customer type, specifically the type of customer, identify objects in order to ensure effect.

Micro-channel with strong mobility and interactivity, which is one of the great advantages of micro-channel marketing. WeChat is based on the relationship between friends "circle" of social media, instant messaging and micro-channel circle of friends as the two most basic function, a considerable proportion in the interactive network. Therefore, the use of micro-channel real estate marketing, if we can seize the two parts of instant messaging and micro-channel circle of friends, it can be a good play very good results. The introduction of quality articles to attract users to forward in the circle of friends of friends to share, the effect is very significant means.

For this convenient micro-channel mobile network applications, micro-channel users both time fixity there randomness, usually in the evening, and so on more occasions before the lunch break, will use a variety of fragments of time to wait for the use of micro-channel, but in this entire weekend of 
rest time, the number of users using micro message there fell a larger scale, so the micro-channel marketing also needs to grasp these cyclical characteristics.

The use of micro-channel marketing, real estate, innovative ideas is also very important. Simply in order to use the micro-channel marketing and is of no value, and the trade-off will lead to weak marketing effectiveness. Although there are many successful cases in the micro-channel marketing, but it is undeniable that the use of micro-channel real estate marketing, there are still a large number of cases of failure. When real estate marketing through micro-channel platform, to focus on the combination of form and content, form and content are equally important to have the idea. This requires marketing team continue to pursue varied and innovative content of the form. Changing form is the first step to attract the user's attention, so-called "smoke powder" process; and innovative content the user can grasp the depth, the so-called "raising flour." Micro-channel mobile marketing, interactive features, as compared to use in marketing traditional marketing methods more flexible. In the use of micro-channel marketing, real estate, it is necessary to pay attention to rely on traditional marketing methods, the role of traditional means, but also pay attention to their own advantage, it cannot be applied mechanically to traditional marketing methods. Particular emphasis on marketing interaction with the user, forcibly push messaging, advertising and other coercive means has gradually been disgusted by the user, and then use this way to promote traditional marketing effect is no longer evident, and therefore must pay attention to marketing and user establishing peer relationships, so that users willing to participate in the micro-channel marketing activities in the past, and even allows users to become part of the marketing team through specific incentives.

\section{Summary}

In the real estate industry sustained and stable development of the background, along with economic development, extensive application of the Internet industry, real estate industry marketing has gradually undergone many changes, and micro-channel self-media marketing as a new marketing tool, gradually showing great advantage of micro-channel from the media in Real estate marketing research, not only to guide the development of the real estate industry, and theoretical study of network marketing also has some value.

In this paper, for the current emerging from the micro-channel media marketing has been studied, and the micro-channel media marketing with real estate marketing since binding. Through traditional marketing theory and real estate marketing, at home and abroad since the content of the media marketing, research, analysis from the media marketing and traditional marketing, the similarities and differences, and through data collection, literature review, case studies, through the micro-channel case from media marketing, summary from micro-channel media applications in the real estate marketing, and based on this analysis and inquiry from the media age trends in real estate marketing, real estate marketing and give advice, provide a reference for real estate marketing theory and practice.

On the theoretical innovation, this paper, in recent years, the direction and development trend of network marketing, network marketing micro-channel marketing, for example from the media, combined with the real estate industry research, to a certain extent, be able to further improve the current network marketing theory, especially since media marketing applications 4P theory proposed real estate WeChat from media marketing 4PM model, and through specific case studies, the relevant theory argues that the traditional marketing theory, which must be supplemented by empirical analysis of the theory was verified. In addition, traditional marketing theory has gradually appearing in the current era of social networks some shortcomings, and since theory and application media marketing effectively compensate for the shortcomings of traditional marketing theory, only seize the current characteristics of the times, to achieve valuable, meaningful innovation.

As the current popular means of network marketing, since the micro-channel media marketing in the real estate marketing has played an important role, but also have shown a lot of remarkable results. Real estate developers, operators, must pay attention to grasp the opportunity to micro-channel from 
the media marketing of rapid development, by mode switching, technological improvements, content services and means of innovation, and give full play micro-channel advantage from media marketing, and focus on strategy, concept focus on method development and innovative thinking, and strive to enhance their competitiveness through powerful marketing tools, give full play to their own advantages, promote marketing effectiveness.

Corresponding Author:

Professor Chunming An, School of Economic Management, Beihua University, 132013, Jilin City, China

\section{References}

1. Tangyan Jie Communication Perspective under micro-channel marketing pros and cons of the news world, 2014,02: 112-113

2. Zhou Lei. Micro-channel advertising communication Forces of Southeast dissemination, 2012 (1) 30 .

3. Li Lei micro letter: 3 million users behind the news and writing, 2013 (4).

4. Su Qiang microblogging action letters and other new media in brand communication in the modern business .2013 (18): 55 .

5. Wen Xin. On the micro-channel to traditional media opportunities. Journalism and Communication, 2013 (5).

6. Feng Hai super micro channel marketing suddenly broke, gold geometric Internet Week, 2012.

7. Qin Kai micro-channel marketing pros and cons of e-commerce in enterprises, 2012 (11): 15.

8. Cheng Xiaoyong 2012 micro-channel marketing ten cases. Modern Enterprise Education, 2013 (3). 